\title{
Workshop Presentation of a Social Wearable That Affords Vulnerability
}

\author{
Ella Dagan \\ University of California, Santa Cruz \\ Santa Cruz, CA, USA \\ ella@ucsc.edu
}

\author{
Ferran Altarriba Bertran \\ University of California, Santa Cruz \\ Santa Cruz, CA, USA \\ faltarri@ucsc.edu
}

\author{
Elena Márquez Segura \\ Department of Informatics and Media, \\ Uppsala University \\ Uppsala, Sweden \\ elena.marquez@ucsc.edu
}

\author{
Miguel Flores \\ University of California, Santa Cruz \\ Santa Cruz, CA, USA \\ mflore048@gmail.com
}

\author{
Katherine Isbister \\ University of California, Santa Cruz \\ Santa Cruz, CA, USA \\ katherine.isbister@ucsc.edu
}

\begin{abstract}
We present 'True Colors,' a social wearable prototype designed to augment co-located social interaction among players in a LARP (live action role play). We designed it to enable the emergence of rich social dynamics between wearers and non-wearers. True Colors is Y-shaped, worn around the upper body, and has distinct front and back interfaces to afford actions taken by the wearer (front), and actions taken by others (back). To design True Colors [3], we followed a Researchthrough-Design approach, used experiential qualities and social affordances to guide our process, and co-designed with LARP designers. 13 True Colors wearables were deployed in a 3-day LARP event, attended by 109 people. Out of all the functionalities and interactivity the device afforded, players gravitated most towards those that emphasized the social value of experiencing vulnerability as a prompt to get together.
\end{abstract}

\section{CCS CONCEPTS}

- Human-centered computing $\rightarrow$ HCI theory, concepts and models.

Permission to make digital or hard copies of all or part of this work for personal or classroom use is granted without fee provided that copies are not made or distributed for profit or commercial advantage and that copies bear this notice and the full citation on the first page. Copyrights for components of this work owned by others than the author(s) must be honored. Abstracting with credit is permitted. To copy otherwise, or republish, to post on servers or to redistribute to lists, requires prior specific permission and/or a fee. Request permissions from permissions@acm.org. UbiComp/ISWC '19 Adjunct, September 9-13, 2019, London, United Kingdom (c) 2019 Copyright held by the owner/author(s). Publication rights licensed to ACM.

ACM ISBN 978-1-4503-6869-8/19/09 . \$ \$15.00

https://doi.org/10.1145/3341162.3345614

\section{KEYWORDS}

Social wearables; wearables; vulnerability; RtD; LARP; embodied interaction; social touch.

ACM Reference Format:

Ella Dagan, Ferran Altarriba Bertran, Elena Márquez Segura, Miguel Flores, and Katherine Isbister. 2019. Workshop Presentation of a Social Wearable That Affords Vulnerability. In Adjunct Proceedings of the 2019 ACM International foint Conference on Pervasive and Ubiquitous Computing and the 2019 International Symposium on Wearable Computers (UbiComp/ISWC '19 Adjunct), September 9-13, 2019, London, United Kingdom. ACM, New York, NY, USA, 2 pages. https://doi.org/10.1145/3341162.3345614

\section{TRUE COLORS}

True Colors is a social wearable, i.e. a wearable that augments co-located social interaction [8]. The main goal in this project was to design a device that enhanced social interaction and enabled the emergence of rich social dynamics between wearers and non-wearers. To support these goals, the front interface was designed to empower the wearer to initiate action, while the back was designed for others to use. We were inspired by prior work on technology co-creation with expert design communities [6, 8]. LARP (live action role play) designers are experts in designing narrative and environments that support rich social experience for their players by utilizing technological and non-technological objects $[9,11]$. We created True Colors by using a Researchthrough-Design (RtD) approach $[4,13,14]$ and co-creation [10] with Event Horizon (EH)'s LARP designers of the New Gyr LARP [5]. We intend to bring one of the prototypes to the workshop to discuss its features in Beyond Individuals: Exploring Social Experience Around Wearables.

Traditionally, the focus in HCI tends to be more on reducing human vulnerabilities. We find "technological fixes" (Winberg cited by [7]) with the aim of resolving vulnerability issues, attempting to make us feel safe, strong and protected. The experience of vulnerability in everyday life 


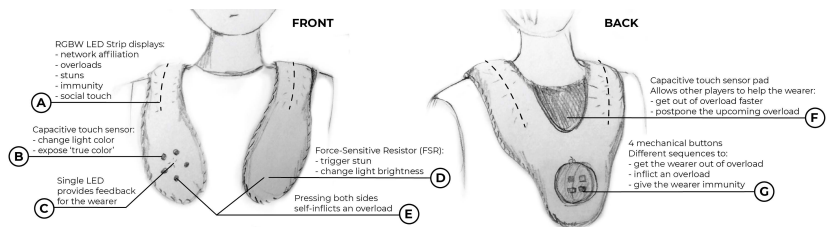

Figure 1: Illustration of functionalities. ${ }^{\odot}$ Ella Dagan.

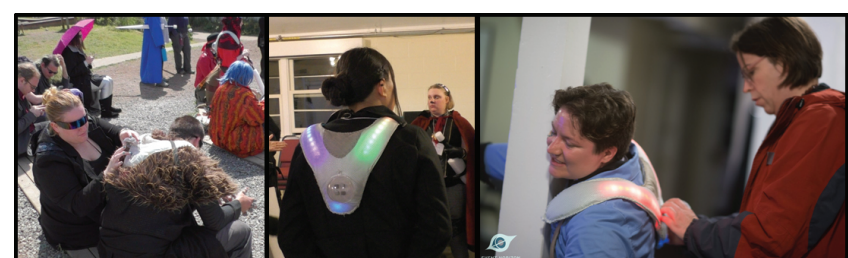

Figure 2: Left and Right: Non-wearer players interact with the back interface of wearers. Center: Device showing ingame immunity mode. ${ }^{\odot}$ Event Horizon.

may be perceived as unpleasant or unwanted, yet research suggests it serves an important function as "the core, the heart, the center, of meaningful human experiences"; a key for wholehearted living among others [1]. True Colors was tested primarily in the field, and provided very promising results regarding its potential to enhance co-located social interaction among players, in particular how players were embracing vulnerability through the use of the wearables [3]. This work extends previous work on wearable technology in LARPs $[2,8,12]$, including supporting emotional resonance, social signaling, and spectator sensitivity (e.g. of moments of weakness) affordances [8]; supporting authentic self-presentation and choice; and supporting overcoming difficulties together (e.g. through social touch). See video demonstration here: https://tinyurl.com/y6xbw8l3.

\section{LIVED EXPERIENCE OF TRUE COLORS}

True Colors affords a variety of social interactions, ranging from friendly to more confrontational. During the LARP, participants could choose which features to use and how.

From a thematic analysis of the collected data, a few design themes other than vulnerability emerged: (i) players considered the wearable to be 'interactable'-it was easy for them to interact with, it felt like a 'real' interface to them, and it also supported their interaction with one another; (ii) the wearable supported role play of identity affiliation, it was easy to tell who was an 'Augment' because they all wore the devices, making them stand out as 'others' and telegraphing their group affiliation and social status; (iii) the wearable enhanced scene building by making scenes more interesting, and players used it to create scenes and improvise around its interactive features; and finally (v) uncontrollable timing, the wearable has a prominent feature triggered based on a timer which created a lot of interesting moments for players. Players referred to this as serendipitous timing that was perfect for the scene/players (but not necessarily for their characters). (For more detail about these findings, see [3].)

\section{ACKNOWLEDGMENTS}

We thank Event Horizon team, all of New Gyr's participants and those who helped produce copies of the design.

\section{REFERENCES}

[1] Brené Brown. 2015. Daring greatly: How the courage to be vulnerable transforms the way we live, love, parent, and lead. Penguin.

[2] Oğuz Turan Buruk and Oğuzhan Özcan. 2018. Extracting Design Guidelines for Wearables and Movement in Tabletop Role-Playing Games via a Research Through Design Process. In Proceedings of the 2018 CHI Conference on Human Factors in Computing Systems (CHI '18). ACM, New York, NY, USA, Article 513, 13 pages. https://doi.org/10. 1145/3173574.3174087

[3] Ella Dagan, Elena Márquez Segura, Ferran Altarriba Bertran, Miguel Flores, and Katherine Isbister. 2019. Designing 'True Colors': A Social Wearable That Affords Vulnerability. In Proceedings of the 2019 CHI Conference on Human Factors in Computing Systems (CHI '19). ACM, New York, NY, USA, Article 33, 14 pages. https://doi.org/10.1145/ 3290605.3300263

[4] William Gaver. 2012. What Should We Expect from Research Through Design?. In Proceedings of the SIGCHI Conference on Human Factors in Computing Systems (CHI '12). ACM, New York, NY, USA, 937-946. https://doi.org/10.1145/2207676.2208538

[5] Event Horizon. 2018. World Database. Retrieved December 31, 2018 from http://www.eventhorizonlarp.com/world-database.html

[6] Katherine Isbister, Elena Márquez Segura, Suzanne Kirkpatrick, Xiaofeng Chen, Syed Salahuddin, Gang Cao, and Raybit Tang. 2016. Yamove! A movement synchrony game that choreographs social interaction. Human technology 12 (2016).

[7] Sean F Johnston. 2018. The Technological Fix as Social Cure-All: Origins and Implications. IEEE Technology and Society Magazine 37, 1 (2018), 47-54.

[8] Elena Márquez Segura, James Fey, Ella Dagan, Samvid Niravbhai Jhaveri, Jared Pettitt, Miguel Flores, and Katherine Isbister. 2018. Designing Future Social Wearables with Live Action Role Play (Larp) Designers. In Proceedings of the 2018 CHI Conference on Human Factors in Computing Systems. ACM, 462.

[9] Elena Márquez Segura, Katherine Isbister, Jon Back, and Annika Waern. 2017. Design, appropriation, and use of technology in larps. In Proceedings of the 12th International Conference on the Foundations of Digital Games. ACM, 53.

[10] Elizabeth B.-N. Sanders and Pieter Jan Stappers. 2008. Co-creation and the new landscapes of design. CoDesign 4, 1 (Mar 2008), 5-18. https://doi.org/10.1080/15710880701875068

[11] David Simkins. 2015. The Arts of LARP: Design, Literacy, Learning and Community in Live-Action Role Play. McFarland.

[12] Loïs Vanhée, Elena Márquez Segura, and Katherine Isbister. 2018. Firefly: A Social Wearable to Support Physical Connection of Larpers. In Extended Abstracts of the 2018 CHI Conference on Human Factors in Computing Systems (CHI EA '18). ACM, New York, NY, USA, Article D311, 4 pages. https://doi.org/10.1145/3170427.3186503

[13] John Zimmerman, Jodi Forlizzi, and Shelley Evenson. 2007. Research Through Design As a Method for Interaction Design Research in HCI. In Proceedings of the SIGCHI Conference on Human Factors in Computing Systems (CHI '07). ACM, New York, NY, USA, 493-502. https://doi. org/10.1145/1240624.1240704

[14] John Zimmerman, Erik Stolterman, and Jodi Forlizzi. 2010. An Analysis and Critique of Research Through Design: Towards a Formalization of a Research Approach. In Proceedings of the 8th ACM Conference on Designing Interactive Systems (DIS '10). ACM, New York, NY, USA, 310-319. https://doi.org/10.1145/1858171.1858228 